\title{
Process for the Implantation of Wind Farms in the Basque Country Autonomous Community
}

\author{
Melchor Gómez $^{(1)}$, Miguel González ${ }^{(2)}$, Inmaculada Zamora ${ }^{(3)}$ \\ Departamento de Ingeniería Eléctrica, Universidad del País Vasco (UPV/EHU) \\ ${ }^{(1)}$ Colina de Beurko, s/n (48902 Barakaldo); ${ }^{(2)}$ Plaza de la Casilla ${ }^{\circ} 3$ (48012 Bilbao); \\ ${ }^{(3)}$ Alameda de Urquijo s/n (48013 Bilbao) \\ iepgopem@lg.ehu.es iepgomam@lg.ehu.es iepzabei@bi.ehu.es \\ Spain
}

\begin{abstract}
It has been analyzed the implantation process of wind farms in scope of Basque Country Autonomous Community (BCAC) through Plan 3É-2005 - Euskadi Power Strategy 2005- that contains planning territorial and sectorial of energy and more concretely Plan Territorial Sectorial (PTS) of wind energy (Decree 104/2002 of May 14), which it is the instrument that fixes the orientation guidelines and criteria to the selection of the suitable locations for the advantage of the wind natural resource and therefore the search of the best territorial arrangement of the wind farms, within the resulting effective arrangement of the Directives of Arrangement of the Territory (DOT). AII it with the objective put in reaching in 2005 to increase the participation of the renewable energies in the final consumption of electrical energy of the Basque Country Autonomous Community of present $2.7 \%$, to $12 \%$ in 2010 , where a $3 \%$ will come from the wind energy. For it, it will be necessary to install a power of $175 \mathrm{MW}$ in Wind farms, with an investment of 142 million euros.
\end{abstract}

\section{Key words}

Wind Energy, Wind technology, Wind power stations, Wind farms, Wind turbine generators systems.

\section{Introduction}

With the objective of regulating the Implantation of Wind Farms in the BCAC, stimulating the installation and its beginning, preserving the respect to natural and cultural means, are due to create conditions that make agile this process. In the Basque Country Autonomus Community the mechanism that has impelled the development of the Aeolian energy has been the Sectorial territorial Plan of the Wind Energy comes to mark the basic criteria, directives and norms that serve as guideline and direction in:

- Potential or theoretical locations Selection those that consider from the power-economic and environmental combined point of view more suitable.

- Establishment of the cogoverning measures of the environmental impact

- $\quad$ Execution and pursuit of the wind farms

That is to say, one is to create an infrastructure able to take advantage of all the aeolian potential available, of an energy that is inexhaustible, natural, renewable and native, simultaneously that we guaranteed also other interests, like environmental or cultural the own ones of of the Basque Country Autonomus Community. To make the one and other compatible, coordinating the diverse interests of the implied agents is also another one of the goal pursueds.

The more appreciable final result of PTS of the Aeolian energy is the identification, valuation and selection of the locations in which a wind farms can be implanted. For the obtaining of these, two conditioners have considered in addition to the saying previously to begin with.

Evaluate the Aeolian potential (this is: the energy that would be able to generate the wind) and to thus detect, without no other consideration, all the possible or susceptible locations of profitable advantage of the Aeolian resource.

Reject those locations that, in spite of counting theoretically on a susceptible Aeolian potential of profitable advantage, present serious incidences in the environmental or are incompatible with the Directives of Arrangement of the Territory.

The studies of location of activities developed with environmental base can be classified in two main typologys, those that study exclusively those locations where it exists resource for the development of the activity and those that they study the affections on the totality of the territory, independently of his capacity to welcome the activity.

Both systems presents advantages and disadvantages. The main advantage that has the study of the locations 
where exists resource is that the analysis of the affections can be made with a level of detail very superior to the second type of studies. And like main disadvantage that it presents the fact is that the modifications of the technologies and systems used in the advantage of the resources can turn profitable locations that when it was made the location study were not it, lacking data on the environmental incidence of the new project. In this case it has been chosen by first of the routes. In order to avoid the enunciated disadvantages, those locations are included that not being profitable their Aeolian operation with the present technology, it can be medium-term.

Also emplacements have been given priority somehow with high capacity that allow to reach such objective using a smaller number of locations, which is important from the environmental point of view.

\section{Foundations of Base.}

\section{A. Plan 3E-2005, Euskadi Power Strategy 2005.}

General frame of performance during period 1.995 2.005. This power strategic Plan is the natural precedent of the sectorial Territorial Plan which tends to the attainment of the marked objectives by this which in relation to PTS it anticipates the increase in the advantage of the renewable resources, the most important increase in the rate of self-supplying of electrical energy and the reduction of the atmospheric emissions.

\section{B. Decree 28/1997, of February11. Directives of Territory Arrangement (TAD)}

Frame of reference for the formulation of the remaining instruments of arrangement (Sectorial Territorial Plan of the wind Energy) regulated in Law 4/1990, of May 31, Territory Arrangement of the Basque Country. The formulation and execution of the sectorial policies are marked to the guidelines as far as the arrangement and to the use of the spaces and the territory for, having between their functions the one "to formulate with global and interrelated character and in agreement with the policy and/or economic plans of the BCAC, the criteria and norms set of that orient and regulate the processes of establishment in the Territory of the different economic and social from the agents public and deprived activities that operates in order to guarantee the necessary territorial balance of general interest for Euskadi and the creation of adapted conditions to attract the economic activity suitable the territorial spaces ".

\section{Proposition no of law approved by the Basque Parliament the 20 of March of 1997}

The Basque Parliament urge to the Basque Government to that through the Industry Department to elaborate a Sectorial Territorial Plan of wind Energy, paying special attention to the participation of the different social agents in the processes from public information and considering the environmental factor like one of most important at the time of writing up this Sectorial Territorial Plan.
D. Decree 114/2002 of May 14. Sectorial Territorial plan of the wind Energy in the BCAC.

The objective of the Sectorial Territorial Plan is the one to identify, to select and to integrate in the arrangement of the territory of the Basque Country Autonomous Community, more suitable the aeolian locations, considering the environmental factor like one of most important. The accommodation in the arrangement will be made through the determination of the zones in which the wind advantage can be a permissible or harnessable activity.

\section{Objectives of the Territory Arrangement Directives in energy infrastructure}

The objectives and criteria in the matter of energy infrastructure emanate of the diagnoses of the power situation of the BCAC and the proposed challenges, simultaneously taking care of the diversification of the source of supply, harnessing the natural gas and fomenting the presence of the alternative energies, and simultaneously coordinating the territorial strategies lending special attention to the planning and investigation workings. And they are possible to be summarized in the following ones:

- To diversity the power plants available, reducing the dependency of petroleum and harnessing the introduction of the alternative energies. Supporting to the projects related to the development and use of renewable energies.

- To foment the performances of conservation and power saving.

- To educate to public opinion in power problematic and the necessity of a rational use of same.

- $\quad$ To adapt power infrastructures to the exigencies derived from the Territorial Model proposed in the Directives.

- To coordinate the power policy of the BCAC with made at level of the State and the European Union and the plans and programs made by the own power societies.

The Sectorial Territorial Plan must gather each one of the programs power, or individual of Partial the Territorial Plans to be able the coordination of the policies of the different power societies with the one from Arrangement of the Territory with object to anticipate, with the greater possible advance, the real ground necessities for the creation of new infrastructures.

\section{Sectorial Territorial Plan of the wind energy in the BCAC}

\section{A. Origin and convenience of the plan}

The electrical energy of wind origin constitutes a power reality, being past, in few years, to have a testimonial 
contribution in the total of primary energy to be able to represent, in some cases, a significant percentage of the power total. The state present of technology allows construction of machines of power important and great reliability of operation, with that, in appropriate places, wind farms of great power which they can generate amounts significant of energy, economically profitable can be constructed. Thus the installation of wind farms in the BCAC can suppose an advance for:

- The reduction of the $\mathrm{CO} 2$ emissions, main provokers of the effect conservatory and the climatic change.

- To contribute to increase the rate of power selfsupplying of the BCAC, which supposes a substantial improvement in a as strategic sector as power.

- To contribute to the supply sources diversification, which will improve, proportionally, the availability, security and competitiveness of the Basque power system.

- To approach the energy generation source to the consumption points, which can allow to equip us with greater margins of freedom and to contribute to the conservation and power saving, reducing to the losses of energy and the environmental impacts derived from the transport from same

- To seat definitively the installation of one aeolian industry in the BCAC, that contributes to the technological development, the improvement of the competitiveness and really to the improvement of the economy and the employ creation. The construction of wind farms supposes a generation of permanent wealth.

\section{B. Objectives}

The wind Energy PTS are applicable in the territory from the BCAC to wind farms that count with more than eight wind turbine generator systems, spill the generated energy to the network and also have an installed power above to $10 \mathrm{MW}$, has like objectives:

- To establish concrete norms of general application, with the objective to discipline and to channel the development of the process of implantation of to wind farms in the BCAC.

- To select the adapted locations more for the implantation of wind farms in the BCAC territory, as well as that such planning is framed within a global policy of arrangement of the territory, with the necessary coordination of the concurrent sectorial interests in the aeolian development.

To proportion to necessary the wind farms for the development of this type of energy, the suitable insertion in the territory; as well as, to guarantee the coordination of the different titles from public intervention in the sectorial orders: power wind, territorial and city-planning

- To serve as useful frame to the ordered development of the wind sector, indicating to the guidelines and orientation criteria that can serve as guide at the time of analyzing and valuing other locations different from the contemplated ones in this PTS for the case that some promoter therefore will indicate them. It is tried yet to reach at least one installed power of $175 \mathrm{MW}$ and one 437,500 annual production of MWh of wind origin, anticipated in the 3É-2005 Plan. Besides to make possible the increase of these objectives and to give capacity a new, in a horizon subsequent to the 2005, whenever the absence of significant negative environmental impacts or the majority social acceptance of the wind farms is confirmed.

\section{Selection of suitable locations}

The election of the emplacements turns out to be fundamental from the point of view of environmental and territorial incidence that have the wind farms without losing of sight the wind theoretical potentials with the current technology. This way the chosen emplacements, after the analysis and confrontation of alternatives, acquire the character of definitive, they are integrated directly and automatically in the territorial arrangement and the municipal city-planning. And its execution, in addition to being possible and attractive for the promotional potentials, will be able to generate electrical energy sufficient to fulfill present and future power objectives. In order to select these locations the following fundamental sequences are made:

- Analysis of the general conditions of wind and the wind zones of the BCAC.

- Process of identification, valuation and selection of locations

○ Technical-economic-power aspects

- Aeolian Potential of BCAC. During this phase the identification of the locations located in the CAPV, or its limits, that have Aeolian capacity, independently of its environmental conditions or the technical viability of its advantage is made. These places constitute the potential locations.

- Irrealizable Potencial. The locations identified in the previous step are put under an analysis of technical viability. In this phase are rejected those locations or parts of such in which "wind" exists resource but the advantage strongly is limited by the technical difficulties of 
accomplishment of the installation. The places that surpass this phase constitute the attainable locations Elimination of locations that do not have technical viability. The places that surpass this phase constitute the attainable locations

○ Environmental aspects.

- Identification of environmental affections classifying them in critics and permissibles.

The critics are those affections, that of not taking cogoverning or ordenadoras measures, would originate an inadmissible impact when surpassing the threshold established by this PTS. Therefore, they are analyzed if the affections critics are avoidable or not by means of the application of cogoverning or ordenadoras measures that eliminate them or mitigate, coming to the desestimación from the locations or parts from such in which affections take place inevitable and critics.

The permissible ones are susceptible of valuation and comparison between the different locations. Finally, another type of affection exists whose study exceeds to present PTS, having specific instruments for its analysis.

- Classification of permissible locations

One double classification of the permissible locations based on its greater or smaller tecnico-economic and environmental suitability is made in this section. It is divided in two subphases.

- Classification of locations based on its environmental affection. New desestimación for environmental reasons.

A specific methodology for the valuation of the permissible affections sets out and makes, integrating itself later in an only value. In the final valuation of the affection, obtains greater weight those factors in which the affection of the Aeolian facilities, seems that priori can be a greater (landscape and birds). In this step it is observed, that although some locations are permissible, the affection produced by them is remarkably superior to the one of the rest. Taking into account which the permissible locations surpass net to the power objectives anticipated in the É-2005 Plan, it is considered advisable to both misestimate locations that emphasize on the others by their environmental impact.
- Classification of locations based on power-economic factors

The permissible locations are classified based on the estimation of their potential power-economic capacity. The factors that are analyzed are the Aeolian potential and the relation between the costs that the installation based on the intrinsic characteristics of the location and the forecast of electricity production originates

- Integrated classification of locations.

In this phase the obtained results are integrated previously. A matrix of double entrance is made, classifying the locations based on its Aeolian capacity and its environmental affection. A matrix of double entrance is made in which the locations will be classified and grouped based on their economic factors technical and its environmental affection. In an end of the table will be the most interesting locations, since they will combine a greater economic-power capacity and a smaller environmental affection. In the opposite end the locations with smaller power interest will be located and greater environmental affection, being therefore less advisable. The rest of locations will be located in intermediate situations throughout the table. The purpose of the integrated classification is the one to facilitate criteria to be able to choose dice in a while as they are the locations or projects, more suitable for the Aeolian advantage, supposing that the requests for the installation of Aeolian parks surpassed the maximum limits that could settle down for the number of facilities, the maximum power installed or any criterion or parameter that were indicated.

There is included later a synoptic picture that serves as guide to understand the methodology continued in the present study in the determination of the wind proposed emplacements. 


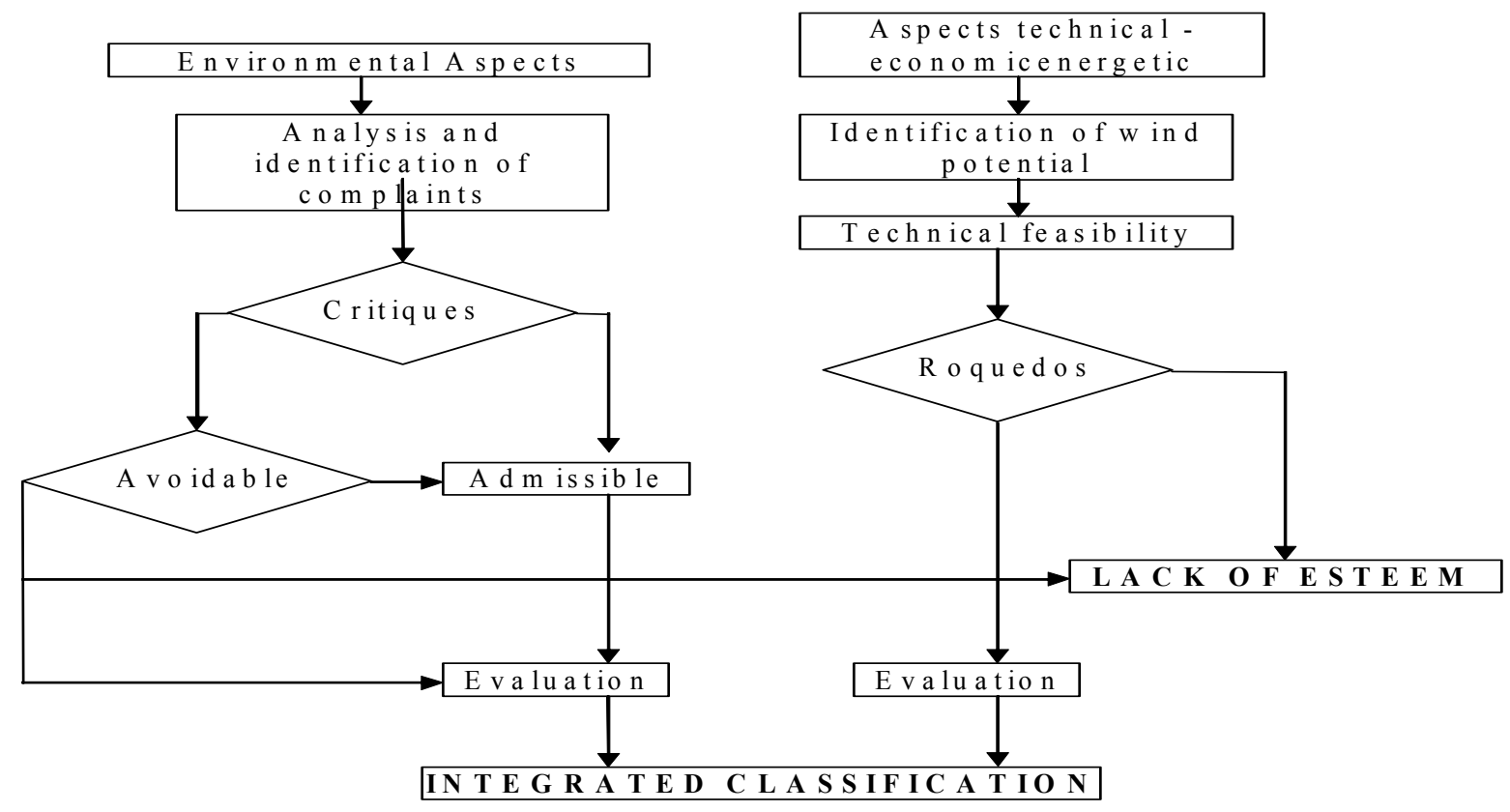

Fig.1. Methodology for the determination and evaluation of wind farms

- Division of locations in two groups.

Group I. Locations which they allow the fulfillment of the power objectives of the 3E2005 Plan with the minimum environmental impact,

Group II Only will allow these locations when the objective difficult for the fulfillment of the anticipated power objectives without resorting to these locations

- $\quad$ Selected Locations. Execution.

The execution of wind farms in the selected locations will need the transaction and approval of the technical projects of the concrete facilities on the part of the Industry Department, and its submission to evaluation of environmental impact on the part of the Environmental Organ of the BCAC.

- $\quad$ Locations nonanticipated in PTS.

The installation of a wind farm of including in the object of this PTS, in a location nonanticipated in the same one, will require its previous modification

- New city-planning arrangement.

In the emplacements selected in the PTS, the implantation of a wind farm and all its auxiliary organizational elements and connected will be a use or permissible activity, whatever it is the classification or qualification of ground and within all the anticipated categories of arrangement in the directive of the medium physicist of the DOT.
- $\quad$ Effects on the effective planning

The definitive approval on the Sectorial Territorial Plan of the wind Energy will affect the city-planning planning affected by the selected locations, in such a way that this one will be tie by the determinations of this PTS and will have to adapt to them in his first revision or modification.

\section{Effects and reach of the plan}

The aeolian energy PTS implies the adaptation of the city-planning plans regulated by the legislation of the ground, adjusting to the rectifications introduced in this plan, because the determinations of PTS prevail over the determinations of the Plans and municipal Norms. And the declaration of public utility of all the actions in him with the object of unavoidable expropriation of necessary lands for its execution, as well as for the imposition and exercise of the servitudes that come to the same aim.

\section{E. Execution and Pursuit of Aeolian Parks.}

The implantation of the wind farms in the selected locations will need the previous transaction the administrative authorization of the facilities and the approval of the "technical project in the terms anticipated in the electrical legislation. Being the Industry Department the competent one for the granting of the administrative authorizations of the facilities. In addition the wind farms will have to be put under the procedure of Evaluation Individualized of Environmental impact that are implanted in the BCAC in agreement with the established thing in Law 3/1998, General of environmental protection of the Basque Country. 
To make an environmental pursuit making a pursuit and "control of the executed performances, with the purpose of verifying its suitable development. In addition it will carry out a pursuit plan that will contemplate the following aspects: collisions; observation of the migration and the sedentary birds; study of the possible aggravating atmospheric circumstances of other affections on the birds.

To make a pursuit of the social acceptance making surveys in the social surroundings immediate to each wind farms, within the following year to its put into operation. To the put into operation of the first 100 installed MW of wind energy, a study of existing general opinion in Euskadi will take place on this type facilities.

To elaborate an annual report of pursuit before the Department of Industry of the Basque Government, a report that will have like minimum the following content:
a) Evaluation of the demand of electrical energy.
b) Production of electrical energy.
c) Justification of the fulfillment of objectives.
d) Evaluation of the operation of the
e) Conclusions of the report of environmental pursuit.

\section{F. Selected locations}

Have been selected 11 locations, the six first belong to group I and the rest to group II

TABLE I. - Selected locations

\begin{tabular}{|l|r|r|r|r|r|r|r|}
\hline & \multicolumn{1}{|c|}{$\begin{array}{c}\text { Wind } \\
\text { speed }\end{array}$} & \multicolumn{1}{c|}{$\begin{array}{c}\text { Net } \\
\text { hours }\end{array}$} & \multicolumn{1}{c|}{$\begin{array}{c}\text { Leng. } \\
(\mathrm{km})\end{array}$} & \multicolumn{1}{c|}{$\begin{array}{c}\text { Wind-T- } \\
\text { generators }\end{array}$} & \multicolumn{1}{c|}{$\begin{array}{c}\text { Power } \\
(\mathrm{MW})\end{array}$} & $\begin{array}{c}\text { Produc. } \\
(\mathrm{GWh} / \mathrm{y})\end{array}$ & $\begin{array}{c}\text { Cost } \\
\left(10^{3} €\right)\end{array}$ \\
\hline Ordunte & 7,3 & 2801 & 12,6 & 60 & 39,6 & 111,1 & 357000 \\
\hline Ganekogorta & 6.8 & 2494 & 1,98 & 20 & 13,2 & 33 & 11900 \\
\hline Oiz & 7,4 & 2884 & 4,88 & 35 & 23,1 & 66,7 & 20825 \\
\hline Mandoegi & 6,3 & 2168 & 7,95 & 39 & 25,7 & 55,9 & 23205 \\
\hline Elgea-Urkilla & 8 & 3264 & 10,06 & 87 & 57,4 & 187,7 & 51765 \\
\hline Badaia & 6,7 & 2308 & 14,51 & 107 & 70,6 & 163,3 & 63665 \\
\hline Kolometa & 7,5 & 2925 & 5,91 & 62 & 40,9 & 119,9 & 36890 \\
\hline Arkamo & 6,9 & 2534 & 7,78 & 65 & 42,9 & 108,9 & 38675 \\
\hline Gazume & 6,8 & 2494 & 1,74 & 17 & 11,2 & 28 & 10115 \\
\hline Montes de Iturrieta & 6,6 & 2233 & 5,91 & 46 & 30,4 & 66,9 & 27370 \\
\hline $\begin{array}{l}\text { Cruz de Alda- } \\
\text { Arlaba }\end{array}$ & 6,8 & 2474 & 4,85 & 34 & 22,4 & 55,6 & 20230 \\
\hline Total & & & 78,2 & 572 & 377,4 & 998 & 340340 \\
\hline
\end{tabular}

\section{References}

[1] Hau, E. Windturbines. "Fundamentals, Technologies, Aplication and Economies ". Springer-Verlag. (2000)

[2] Decreto 104/2002, de 14 de mayo, Boletín Oficial del País Vasco de 5/ 06/ 2002.

[3] Real Decreto 2818/1998, de 23 de diciembre, B.O.E. $n^{\circ} 312$ de 30/ 12/ 1998.

[4] Ley 54/97 del Sector Eléctrico, B.O.E. no 285 de 28 de noviembre de 1997.

[5] J.L. Rodríguez Amenedo, J.C. Burgos Díaz, S. Arnalte Gómez. Sistemas Eólicos de Producción de Energía Eléctrica. Editorial Rueda SL. Madrid 2003.

[6] IDEA. Wind Energy in Spain 2002. Current Status and Prospets.

[7] Departamento de Industria, Comercio y Turismo del Gobierno Vasco. 